\title{
"They are wearing other people's suits": Delusional Misidentification Syndromes
}

\author{
M. Mendonça Bettencourt, P. Sousa Martins, C. Bragança Rodrigues, F. Pereira. \\ Unidade Local de Saúde do Nordeste, Departamento de Psiquiatria e Saúde Mental, Bragança, Portugal
}

\section{Delusional Misidentification Syndromes}

Capgras' syndrome: belief that a person, usually emotionally related, has been replaced by an exact or almost exact double, an imposter. Hypo-identification. Most common and best known delusional misidentification syndrome (DMS).

Fregoli's syndrome: misidentification of an unfamiliar person as a familiar one. Hyper-identification.

Intermetamorphosis: belief that others undergo radical changes in physical and psychological identity, becoming a different person.

Subjective doubles: belief in the existence of a physical double of the self, with a different psychological identity.

\section{Pathogenesis}

DMS as a cognitive process : failure to identify the subject despite the apparent functioning of the recognition process.

The dual-lane model postulates that Capgras' syndrome results from an attempt to give meaning to a diminished emotional response in the presence of a significant other

Other factors postulated as involved are the failure of the system of evaluation of convictions, anomalies in salience or in abductive inference processes.

\section{Case report - Capgras and Fregoli}

Identification: 43 year old single woman. Lived with her mother in a small inland village. Worked as a Clinical Analysis Technician. History of several depressive episodes in the past.

Clinica History: after her father's death, to whom she was very close, she developed the belief that her mother's caregiver had been substituted by someone with the same height, wearing a suit that resembled her. This happened in the context of a wider paranoid delusion: her brothers were trying to harm her and their mother.

She came voluntarily to the ER complaining about dizziness which she believed to be caused by her brothers poisoning the water in the house where she lived. She was voluntarily committed to psychiatry ward where she reported that she had been hearing voices since she was 20 years old. These voices would depreciatively comment her behaviour.

During the internment she believed that several other inpatients and visits were people she knew disguised in order to watch her. She thought this was all part of a game that she had to win and these delusions caused her a lot of anguish.

Brain MRI and bloodwork showed no abnormalities.

She was later diagnosed with Schizoaffective Disorder and medicated with Paliperidone and Sodium Valproate with almost total remission of symptoms.

Capgras possible underlying diagnosis
Schizophrenia
Schizoaffective
Transient Psychotic episode
Delusional disorder
Bipolar affective disorder
Psychotic depression
Delirium
Dementia
- Parkinson's disease dementia
- Lewy body dementia
- Alzheimer's disease
- Vascular
Organic delusional disorder
Drug related
Traumatic Brain Injury

\section{Results and Conclusion}

Delusion Misidentification Syndromes covers different phenomena thought to involve failure in the identification process. Capgras is the most common and well known of them. It is usually related with another delusion which was the case with this patient.

She presented both Capgras and Fregoli delusions, in the context of a wider paranoid delusion associated with auditory hallucinations.

Usually these misidentifications can be associated with hostility towards the impostor, which was not the case.

The case described concerns a primary psychiatric diagnosis but DMS may be a manifestation of organic disease, demanding a careful screening in order to exclude their presence, specially in elder patients. 